\title{
MANIFESTATIONS OF SUPRARENAL INSUFFICIENCY OCCURRING WITH PITUITARY TUMOURS
}

\author{
BY \\ ANTONY JEFFERSON* \\ From the Department of Neurological Surgery, the Radcliffe Infirmary, Oxford
}

The urgent symptoms which frequently result from compression of the optic nerves and chiasm have focused attention upon themselves so that some of the manifestations of adrenal cortical insufficiency secondary to "pituitary tumour" have received scant notice. This is not to say that they are totally unknown, but they form a submerged body of knowledge to which relatively little importance is accorded. Now that cortisone and its allied and related substances provide for the first time an effective treatment of this condition, the neurologist or neurosurgeon, who usually has the care of such patients, must be fully aware of the possible ways in which these patients' symptoms may present. The symptoms and signs of adrenal failure can closely mimic those of organic brain disease, so that a patient in crisis from adrenal failure may be mistakenly regarded as suffering from serious intracranial mischief. This may occur in primary suprarenal insufficiency, but when it happens to a patient whose suprarenal failure is secondary to an already recognized pituitary chromophobe adenoma, the temptation to ascribe the clinical picture to a massive extrasellar extension of the tumour is almost irresistible. In either case a mistake in diagnosis may cost the patient his life, for full radiological investigation or surgical exploration will likely prove disastrous when in reality the appropriate and urgent need is for adrenal cortical hormones. Moreover, in lesser degree, adrenal cortical insufficiency not only increases the risks of operation, but may cut short the patient's span of life, or may be responsible for ill-health which either prevents the patient's return to work or greatly decreases his efficiency and enjoyment of life.

This paper is concerned with manifestations ascribable to adrenal cortical hypofunction in 135 cases of pituitary chromophobe adenoma (of which 124 were histologically verified) and in 31 cases of Rathké pouch cyst. The youngest patient with a

* Now at Department of Neurosurgery, United Sheffield Hospitals. pituitary adenoma was aged 18 at the time of admission to hospital for the treatment. In order to make the two groups of cases comparable, 28 cases of Rathké pouch cyst which required admission below the age of 18 have been excluded from this survey.

\section{Material}

It has been possible to trace the records of 135 cases of pituitary chromophobe adenoma. Of these the lesion was histologically verified on 124 occasions, and in the remainder there were firm clinical and radiological grounds to sustain the diagnosis. Of those with Rathké pouch cysts, 19 had been histologically verified, and the remaining 12 had radiological evidence of typical suprasellar calcification. A small group of patients was rejected because, although either a pituitary chromophobe adenoma or a Rathké pouch cyst was suspected, there were neither satisfactory histological nor radiological findings to differentiate between them. I have personally examined 52 of the patients with a chromophobe adenoma, and one half of those with Rathké pouch cysts who are still alive. For all the data on the remainder of the patients (some of whom are now deceased) I am indebted to the records of the Department of Neurological Surgery at the Radcliffe Infirmary. Most of the operations on these patients were carried out by the late Professor Sir Hugh Cairns and by Mr. Joe Pennybacker.

\section{Case Histories Illustrating Suprarenal Failure}

The usually accepted description of hypofunction of the suprarenal glands includes the following symptoms: asthenia, anorexia, nausea, vomiting, and diarrhoea; abdominal pain may occur, and also cerebral disturbances such as restlessness, depression, drowsiness. There may be troublesome hiccoughs. Pigmentation is common but not invariable; the blood pressure is usually low. As a " crisis " develops there may be vomiting, diarrhoea, fever, and even abdominal pain severe enough to simulate an acute 
abdominal crisis. When the Addisonian crisis is fully developed the blood pressure falls to low levels, and at times cannot be recorded. From this point the patient can usually only be saved by immediate and vigorous treatment.

In the literature of the English language, apart from an admirable paper by Cushing (1913) entitled "Psychic Disturbances Associated with Disorders of the Ductless Glands", there has been relative neglect of those aspects of suprarenal failure which were first described by the term "l'Encéphalopathie Addisonienne" (Klippel, 1899) and which have been amplified by French writers since that time. These writers have stressed that among the symptoms associated with suprarenal failure are personality changes, restlessness and delirium, headache, vomiting, photophobia, and stiffness of the neck (Frette, 1913), convulsions and coma (Lebrun, 1937), whilst terminal opisthotonic attacks with extensor spasms have also been reported (Gosset, 1941). In the American literature, Engel and Margolin (1941) have described neuropsychiatric disturbances in Addison's disease, but they did not include the "pseudomeningitic" form of Addisonian encephalopathy, first described by Sergent in 1903.

The following case history, which is that of a man with primary suprarenal failure, provides a dramatic instance of the cerebral symptoms which may occur as the result of acute suprarenal insufficiency. (This patient was admitted to the Radcliffe Infirmary under the care of Dr. A. M. Cooke, and I am indebted to him for permission to record these details.)

Case 1.-A man aged 32 (RI 198915/54) had been in hospital five months earlier because of loss of weight, fatigue, and vomiting after meals. He had lost just over 2 stones in three months. Physical examination disclosed no abnormalities: blood pressure $105 / 80 \mathrm{~mm}$. $\mathrm{Hg}$; blood sedimentation rate $57 \mathrm{~mm}$./hr. (Westergren). He was kept under observation as an out-patient, and apart from loss of energy and failure to gain weight he had no significant complaints. However, when a radiograph of the chest showed for the first time signs suggestive of a tubercular apical infection, he was admitted as a matter of urgency for gastric lavage and reassessment. On the sixth day after admission, he developed malaise, abdominal discomfort and diarrhoea, but the following day these symptoms subsided. From that time on the patient appeared increasingly anxious about himself. On the thirteenth day after admission (May 24, 1955) treatment with streptomycin, para-amino-salicylic acid (P.A.S.), and iso-nicotinic acid hydrazide (I. N. H.) was begun. The patient vomited before the first treatment was given, and that night was doubly incontinent, although on the following morning he was cooperative, was not confused, and complained only of slight dizziness on sitting up suddenly. Because of the development of incontinence as an isolated symptom, tuberculous meningitis was suspected, and a lumbar puncture was performed (May 25,
1955). Only $0.5 \mathrm{ml}$. of fluid could be obtained, but it contained no red or white cells and was quite colourless; radiographs of the skull were normal. By May 27 he was extremely drowsy, slightly restless and confused. He was doubly incontinent. He would obey only very simple commands. His skin was very dry, and on his face there were fine white cracks which had an appearance reminiscent of a thin layer of dried shaving soap. There was no abnormal skin pigmentation. There was some neck stiffness, and later in the day Kernigism was observed. All the tendon jerks were very sluggish; there was a minimal weakness of the right side of the body, and both plantar responses were equivocally extensor. A lumbar puncture was again attempted, but no fluid at all could be aspirated, although the operator was satisfied that the needle was in the correct position. About midday on May 27 signs of profound peripheral vascular collapse (blood pressure $60 \mathrm{~mm}$. $\mathrm{Hg}$ systolic) were evident. At this point suprarenal insufficiency seemed possible, and blood studies showed the following values: Serum sodium $117 \mathrm{~m} . \mathrm{Eq}$./litre, serum potassium (in slightly haemolysed blood) $10.2 \mathrm{~m}$.Eq./litre, and plasma chloride $80 \mathrm{~m}$.Eq./litre. He immediately received a large quantity of normal saline intravenously, together with $100 \mathrm{mg}$. of hydrocortisone intravenously, $30 \mathrm{ml}$. of " eucortone" intravenously, $10 \mathrm{ml}$. of " eucortone" intramuscularly, and $10 \mathrm{mg}$. of desoxycorticosterone acetate (D.O.C.A.) intramuscularly. A stomach tube was passed, and by this means $25 \mathrm{mg}$. of cortisone was given four-hourly. Three hours after the treatment began, he was responding a little more readily, and his blood pressure had not fallen any further. Seven hours after treatment began, when he was better hydrated and had passed normal urine, a lumbar puncture was successfully performed. The pressure was still low, but this time at least $3 \mathrm{ml}$. of fluid was obtained. The analysis of this fluid was not compatible with a diagnosis of tuberculous meningitis. By the morning of May 28, the patient was greatly improved. He was conscious and rational, and he had amnesia for the events of the preceding day. His neck was still stiff, but less so than before. His blood chemistry now approached normal: serum sodium $136 \mathrm{~m}$.Eq./litre, serum potassium $5.6 \mathrm{~m}$.Eq./litre, plasma chloride 96 m.Eq./litre. Next day his appearance and demeanour, which were almost those of a normal subject, made a striking contrast with his moribund state only 36 hours previously. On June 2, it was observed that whereas previously he had been drowsy, hyper-reactive, querulous, and in general " not like his normal self", he was now cheerful and cooperative and had an excellent appetite. The dry scaling of the skin of his face had been a feature from which he had suffered for several years. He had found it necessary to use "lanoline" frequently to keep it in check. This scaling became less evident during treatment with cortisone. The electroencephalographic accompaniments of this illness were interesting and have been illustrated and discussed elsewhere (Boselli and Jefferson, 1957, Case 2).

This patient's progress subsequently was satisfactory; treatment of the tuberculosis was completed, he gained weight, and remained on cortisone by mouth $(12.5 \mathrm{mg}$. t.d.s.) and in excellent health. 
The next case history indicates that cerebral symptoms due to chronic primary suprarenal insufficiency may develop more insidiously. (This patient was admitted to the Churchill Hospital, Oxford, under the care of Dr. E. M. Buzzard, and I am grateful to him for permission to record these details.)

Case 2.-A man of 59 (RI 177548/55) first attended the Out-patient Department two years before his hospital admission, and was said in the past to have had a slightly elevated blood pressure. - Four months before his first attendance he lost $1 \frac{1}{2}$ stones over a period of three months, and began to suffer from fatigue. His skin was dry and ichthyotic in type, and was pigmented over the sacrum and chest. The skin was peeling over his face. His blood pressure was $140 / 90 \mathrm{~mm}$. Hg. He was kept under observation, during which time he complained a lot of the cold. Finally, he became suddenly unconscious for a period of one and a half hours, and was thought to have had an epileptic attack, although no convulsions were witnessed. He was subsequently admitted to hospital for investigation with the chief complaints of lack of energy and lethargy. The peeling of the skin of the face was still evident at the time of his admission, and indeed the patient stated that this phenomenon began at the same time as the lethargy and loss of weight. His blood pressure was $140 / 100 \mathrm{~mm}$. Hg. There were no abnormal neurological signs. The pressure at lumbar puncture was only $40 \mathrm{~mm} . \mathrm{H}_{2} \mathrm{O}$, and the fluid showed a protein level of $60 \mathrm{mg}$. $/ 100 \mathrm{ml}$. and no cells. The serum sodium was $130 \mathrm{~m}$.Eq./litre, serum potassium $4.7 \mathrm{~m} . \mathrm{Eq}$./ litre, and plasma chloride $100 \mathrm{~m}$.Eq./litre. The skull radiograph was normal. On July 15,1955 , while having a barium meal, he fainted and became pale, cold, and clammy, with a very feeble pulse. The barium meal showed no abnormality, and on return to the ward his blood pressure was $130 / 80 \mathrm{~mm}$. $\mathrm{Hg}$.

Because this patient looked so thin and ill, malignant disease was suspected, although no primary tumour had been detected. Since he was thought to have had a fit and there were left temporal " epileptic looking " patterns in the E.E.G., arrangements were made for air encephalography. The encephalogram was performed without incident on July 21, but the following day the patient had a generalized headache, nausea, and vomiting. At 8.30 a.m. on July 23 , he was found to be conscious and able to converse, but he felt weak and he looked severely ill. His pulse was extremely feeble and his blood pressure could not be measured. Abnormalities of the blood chemistry had now developed; serum sodium $129 \mathrm{~m}$.Eq./litre, serum potassium $5.7 \mathrm{~m}$.Eq./litre, and plasma chloride 90 m.Eq./litre. The plasma bicarbonate was $17 \mathrm{~m} . \mathrm{Eq}$./litre. Before the results were available, an intravenous drip containing noradrenaline was begun, as it seemed that he would otherwise die of hypotension. Although the biochemical changes were relatively slight, treatment as for an Addisonian crisis was begun, and he received $100 \mathrm{mg}$. of hydrocortisone intravenously, and large quantities of intravenous normal saline. In addition, cortisone, $25 \mathrm{mg}$. six-hourly by mouth, was started. From this time on there was steady improvement, but he could not be weaned from the noradrenaline until 18 hours after the treatment of the Addisonian crisis began. By this time he had a blood pressure of $110 / 70 \mathrm{~mm}$. Hg. His blood chemistry improved rapidly, and it was soon possible to reduce the oral cortisone to a maintenance dose of $12.5 \mathrm{mg}$. b.d. At the end of the first five days of cortisone treatment, it was remarkable that the scaling of the skin of his face was far less evident. He has remained fit since his discharge from hospital, and he still continues on the same dose of cortisone.

When severe anterior pituitary hypofunction is associated with pituitary tumour, defective function may exist in several, or in all, of these endocrine organs whose normal function depends upon the integrity of the anterior pituitary gland. The features described below of a patient with a pituitary chromophobe adenoma effectively illustrate the outstanding part which secondary suprarenal failure may play in the production of symptoms and signs.

Case 3.-A man of 63 (RI 179989/55) was married and had three grown-up children. He never required to shave regularly until he was 26 years old, and even then only needed to shave every second day in order to preserve a tidy appearance. He was conscious of the fact that throughout his life he had had less body hair than most of his colleagues.

For three years before admission the patient had been aware of diplopia, but only in the last six months did he manifest a definite weakness of the right external rectus muscle. Two months later he developed a right-sided herpes zoster ophthalmicus and from that time onwards he lacked energy and would often have a headache on waking. Five weeks before admission he became progressively unwell, with a feeling as though he were developing a severe cold. After five or six days he was afflicted by pain in his back that became so severe that he retired to bed. Shortly after this he awoke one night with severe occipital pain, and for the next 36 hours he lay, taking very little interest in his surroundings and groaning with pain. He then began to vomit repeatedly, and after four days in bed at home the right eyelid began to droop. With this development an intracranial aneurysm was suspected, and he was admitted to hospital elsewhere. He was found to be conscious and cooperative, though mentally slow. He had a complete ophthalmoplegia on the right. He remained in hospital, and his headache gradually subsided, but he became more drowsy. On September 18, 1955 (a little more than three weeks after his admission to hospital), he suddenly developed ptosis of the left eye, and was found to have a paralysis of the left third and fourth cranial nerves. He had mild fever. On September 19 he became delirious and was admitted to the Radcliffe Infirmary on September 23. He was found to be confused, demented, and disorientated. He was not definitely dysphasic. There was no neck stiffness. Both fundi were pale, indicating optic atrophy, but the discs showed no swelling. There was complete bilateral ptosis, and indeed, with the exception of abduction of the left eye and a feeble light reaction of the left pupil, 


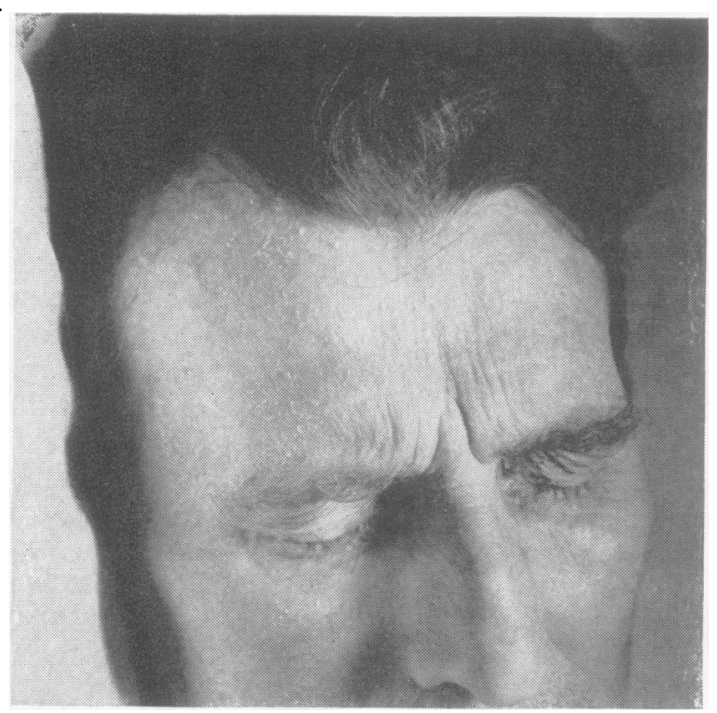

FIG. 1.-Note fine dry scales on the facial skin, particularly that of the forehead (Case 3).

there was complete bilateral ophthalmoplegia. The remainder of the neurological examination disclosed very sluggish or absent tendon reflexes throughout, and both plantar responses were absent. Blood pressure was $120 / 85 \mathrm{~mm}$. Hg. The skin was dry and was neither unduly pale nor pigmented. There were dry scales on the facial skin (Fig. 1). There was sparse axillary hair and a female distribution of pubic hair. Analysis of the cerebrospinal fluid (C.S.F.) showed a protein content of $95 \mathrm{mg} . / 100 \mathrm{ml}$., 9 polymorphs, 28 lymphocytes, and no red blood cells per c.mm. The radiographs of the skull showed an expanded and eroded sella turcica suggestive of a pituitary adenoma. On September 26 the blood chemistry was: serum sodium $135 \mathrm{~m}$.Eq./litre; serum potassium $4.9 \mathrm{~m} . \mathrm{Eq}$./litre, and plasma chlorides $102 \mathrm{~m}$.Eq./litre. The water metabolism was studied under difficulties because of the patient's confused state, but in four hours after the ingestion of $30 \mathrm{oz}$. of water only $8 \mathrm{oz}$. of urine was excreted (corresponding to $27 \%$ of the ingested fluid). Under the circumstances of the case, this finding was taken to indicate adrenal cortical hypofunction, an inference which was backed by the fact that later, when receiving cortisone, more than $100 \%$ of the water "load" was excreted within four hours of its ingestion.

A chromophobe adenoma of the pituitary gland was diagnosed and bilateral invasion of the cavernous sinus was indicated by the bilateral ophthalmoplegia. In order to explain the profound dementia an upward extension of the tumour into the third ventricle was postulated. Because of recent experience of the possible dangers of intracranial air injection in the presence of adrenal cortical hypofunction ( $c f$. Case 1 in Jefferson, 1956, and Case 2 above), cortisone therapy was begun three days before a lumbar air encephalogram was performed (October 1, 1955). The radiographs showed (Fig. 2) absolutely no sign of suprasellar extension of the tumour. Later, when $\overline{\mathbb{D}}$ the patient became cooperative, it was possible to show that the only defect in the visual fields was a slight and 0 partial hemianopia affecting the temporal field of one eye alone. This finding was in keeping with the evidence of the air studies. It was concluded that the mental of symptoms were the result of metabolic disorder. The $\delta$ patient initially received cortisone, $25 \mathrm{mg}$., t.d.s., dried thyroid tablets, 0.5 g., b.d., and $50 \mathrm{mg}$. of methyl $\stackrel{\overrightarrow{2}}{\overrightarrow{2}}$ testosterone dissolved sublingually each day. The corti- sone was subsequently reduced to $12.5 \mathrm{mg}$. t.d.s. On $\overrightarrow{\overline{\overrightarrow{5}}}$ this régime he improved remarkably, though not immediately, and by October 12 he ended a period of amnesia that dated from August 21, and he was no longer demented or uncooperative. A course of radiotherapy $\frac{\bar{\rho}}{\vec{D}}$ directed to the pituitary gland was given. With the im- $\mathbb{D}$ provement in the mental sphere, there was a corresponding dramatic change in the electroencephalogram (see $\mathrm{c}$ Boselli and Jefferson, 1957, Case 1).

Considerable drowsiness, irritable bad temper, and incontinence are features which occur at times following operations upon the region of the pituitary gland. It is usual to ascribe these symptoms to disturbance of the hypothalamus due to oedema $N$ developing in the neighbourhood of the operation is site. However, there are certain features about these post-operative symptoms which are reminiscent of Addisonian encephalopathy. The following fact about the incidence of these changes also suppos this interpretation, although clearly " encephal pathy " rather than hypothalamic disturbance cannot be invoked in every instance.

Mental disturbances in the post-operative phase occurred in 20 cases out of 67 males with pituitary

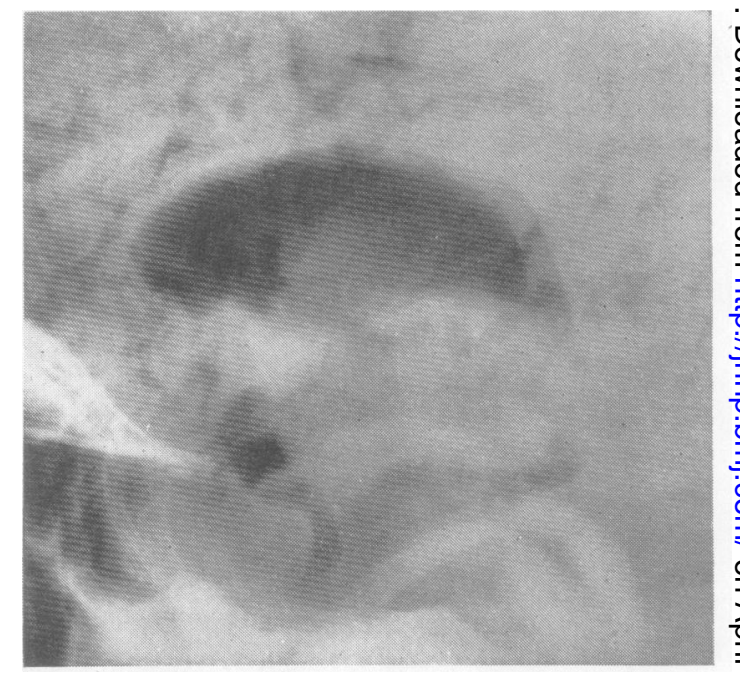

FIS. 2.-Lumbar air encephalogram. Lateral radiograph. Note $\mathcal{N}$ enlarged pituitary fossa but complete absence of supraseller extension: third ventricle undeformed. 
chromophobe adenoma. (Indeed, the incidence of post-operative mental changes in the male cases was $35 \%$ if the few cases in which there was death in the early post-operative phase or else inadequate information in the record are withdrawn from consideration.) Of these 20 cases, no fewer than 14 had considerable features of "hypopituitarism" in the form of pallor and relative hairlessness of face or body. Mental changes in the post-operative phase occurred in nine of the 50 females with a chromophobe adenoma, and, of these nine cases, six had evidence of hypopituitarism. In contrast, among the patients with Rathké pouch cysts, only two patients were hypopituitary of the nine who showed post-operative mental changes. With a Rathké pouch cyst the mechanism of these mental changes is probably more often due to hypothalamic disturbances.

The following case provides an example of postoperative changes probably related to adrenal cortical hypofunction.

Case 4.-A medical practitioner of 36 (RI 20284/43) had an uncomplicated right sub-frontal operation for a pituitary chromophobe adenoma performed by Professor Cairns. This man had a blood pressure of $100 / 70 \mathrm{~mm} . \mathrm{Hg}$. and shortly before admission the systolic pressure had been recorded on one occasion at $90 \mathrm{~mm}$. $\mathrm{Hg}$. In addition, there was very little hair on the limbs, no axillary hair, and sparse pubic hair. The operation was carried out on December 20,1943, and that night his state of consciousness seemed normal. On December 21, he was fully conscious but mute, and on December 22 he began to be doubly incontinent and both plantar responses were extensor. The next day he was very drowsy, and on the eleventh post-operative day Professor Cairns wrote as follows:

"Still mute. At times very difficult to rouse, but will sit up and feed himself. Incontinent of urine and faeces ... No trace of hemiparesis now; both plantars flexor; ... . Some scaling of the skin, especially on the forehead. Blood pressure $70 / 40 \mathrm{~mm}$. Hg. Lumbar puncture pressure $160 \mathrm{~mm}$. $\mathrm{H}_{2} \mathrm{O}$ "'.

On January 6, 1944, the systolic blood pressure was recorded at the level of $100 \mathrm{~mm}$. $\mathrm{Hg}$. for the first time in the post-operative phase. Slowness of movement and incontinence continued to be features of the convalescence for about a month. At the end of that time the patient began to improve, but the blood pressure remained low and was only $100 / 70 \mathrm{~mm}$. Hg. when he was at last well enough to leave hospital two months after his operation.

Symptoms of adrenal cortical hypofunction may persist for many years so that the patient becomes used to the occasionally inconvenient episodes and accepts them. For example, one patient with a Rathké pouch cyst, diagnosed by radiological means at the age of 32 but never operated on, had been under periodic observation for 19 years. By then his blood pressure was $80 / 50 \mathrm{~mm}$. $\mathrm{Hg}$, his water metabolism was typical of suprarenal insufficiency, and he was suffering from lack of energy and repeated " bilious attacks" with headache and gastrointestinal upset. These symptoms interfered considerably with his capacity to work. His water metabolism was restored to normal by cortisone. On a régime of cortisone, $12.5 \mathrm{mg}$., b.d., the bilious attacks ceased abruptly and his "energy" was progressively improved.

These cases show that pallor without pigmentation, scaliness of the skin of the face, mental confusion, meningism, incontinence, headache, and gastrointestinal disorders are all possible manifestations of hypo-adrenalism in patients with pituitary disease. It should be said that these changes may occur in patients before visual disorders have occurred, they may accompany the development of the visual symptoms, or may develop while the patient is in hospital awaiting operation. The removal or the destruction of the blood supply of a functioning pituitary tumour at operation may precipitate "Addisonian" signs and at a later date radiotherapy directed to the pituitary fossa may have the same effect. It is thus necessary to be aware of and to look for the signs of hypo-adrenalism at all stages of the life history of these pituitary " tumours". Because the pallor of the "hypopituitary" patient can usually be corrected by cortisone, and because it seems likely that sparseness of body hair is linked with adrenal cortical hypofunction, it is possible that an approximate notion of the incidence of adrenal cortical dysfunction among these patients may be obtained from a study of the incidence of clinical hypopituitarism. For the chromophobe adenomata this was $66 \%$ of the males and $37 \%$ of the females. For the Rathké pouch cysts, after excluding cases below the age of 18 , the incidence of hypopituitarism was $47 \%$ of the males and $37 \%$ of the females.

Considering those patients who have died, it is impossible in retrospect to make an accurate assessment as to whether correction of a hormonal deficit would have prolonged their lives after treatment, or would have carried them safely through an operation. However, in a few cases the likelihood that death occurred because of adrenal cortical failure seems very high, and in other examples there is a reasonably strong possibility that this was so. Table 1

TABLE I

ANALYSIS OF KNOWN FATALITIES IN THE SERIES

\begin{tabular}{l|c|c|c|c}
\hline & \multicolumn{2}{|c|}{$\begin{array}{c}\text { Pituitary } \\
\text { Chromophobe } \\
\text { Adenoma }\end{array}$} & \multicolumn{2}{|c}{ Rathké Pouch Cysts } \\
\hline & Male & Female & Male & Female \\
\hline $\begin{array}{l}\text { Total known deaths } \\
\text { Deaths ascribed to } \\
\text { endocrine failure }\end{array}$ & 15 & 16 & 7 & 8 \\
\hline
\end{tabular}


shows the incidence of these cases compared with the total number of known deaths from all causes.

Three features of anterior pituitary hypofunction which are probably also related to secondary adrenal failure must now briefly be considered.

\section{Rheumatism}

Of the total of 135 patients with pituitary chromophobe adenoma, 16 had manifestations of " rheumatism ", and the incidence was distributed equally between the two sexes. These varied from very mild to quite severe changes.

Case 5.-An example of the mild changes is provided by a man of 46 (RI 189806) who had had visual disturbances for six months. Two weeks before admission he began to ache in all his joints. All the large joints were affected, and he developed stiffness of the middle fingers of both hands. However, these symptoms subsided following his admission to hospital for operation; they did not recur.

A more severe type is illustrated by the following case:-

Case 6.-This woman (RI 147353/51) was aged 49 at the time of her admission to hospital for treatment of a pituitary adenoma. At the age of 41 her periods had begun to be less frequent, and the following year she had been subjected for the space of 12 months to intermittent headaches of bursting quality. At the age of 45 she had developed an acute attack of rheumatism, with pain in the lower part of the spine and involvement of the shoulder, hip and knee joints bilaterally. She was in bed for three weeks, and her convalescence occupied two months. Failure of vision was not observed until nine months before admission. She continued intermittently to be subject to stiffness and pain in the joints right up to the time of operation, and for the first year after it.

\section{Hypoglycaemia}

Hypoglycaemia has been described in association with a pituitary chromophobe adenoma (e.g., Foley, Snell, and Craig, 1939). However, it is not a common occurrence, for in this series only three patients had symptoms probably referable to hypoglycaemia, and only nine patients out of a total of 56 studied had a fasting blood sugar of less than $70 \mathrm{mg} . / 100 \mathrm{ml}$. The lowest fasting level encountered was $50 \mathrm{mg} . / 100 \mathrm{ml}$., and this was in a woman with very severe long-standing hypopituitarism who was subject to episodes of coma which may have resulted from a low blood sugar (Case 7 described below). One male patient had symptoms which might possibly have resulted from hypoglycaemia. The third patient, a woman aged 56 (RI 93882/48) underwent an intracapsular removal of a pituitary chromophobe adenoma. Six months later she began to get fainting attacks which consisted of a feeling of intense hunger accompanied by a cold sweat. She could just manage to settle herself in a chair before she became unconscious. There was no incontinence or tongue biting, but there was some jerking of the limbs. For a year these attacks occurred some three or four times per week, but after it was suggested that the attacks were hypoglycaemic and that they could be avoided by taking frequent small meals, she became completely free of the full-blown episodes. If she fancied an attack was coming upon her she could avert it by taking food.

Since spontaneous hypoglycaemia has been described in association with atrophy of the suprarenal glands (Rushton, Cragg, and Stalker, 1940) it seems likely that the hypoglycaemia associated with " pituitary tumour" is yet another manifestation of secondary adrenal cortical hypofunction.

\section{Low Fluid Turnover and Constipation}

In a few instances of adrenal cortical hypofunction secondary to pituitary tumour collection of urine over a period of 48 hours has shown a total volume as low as $700 \mathrm{ml}$. Indeed, accurate records indicating an abnormally low fluid turnover constitute one of the features whereby, among these patients, severe hypopituitarism may be recognized from the char[D alone. Perhaps the constipation which may some times be a feature of anterior pituitary hypofunction (cf. Goetsch, 1914) results from an abnormally smal fluid intake. But, whatever the cause, cessation of long-established constipation has been closely and unmistakably linked in some patients with pituitary "tumours" with the beginning of hormone replacement therapy. Table II shows the incidence of this disorder in the various groups of patient.

TABLE II

THE INCIDENCE OF CONSTIPATION AS A SYMPTOM

\begin{tabular}{l|c|c|c|c}
\hline & \multicolumn{2}{|c|}{$\begin{array}{c}\text { Chromophobe } \\
\text { Adenomata }\end{array}$} & \multicolumn{2}{|c}{$\begin{array}{c}\text { Rathké Pouch } \\
\text { Cysts }\end{array}$} \\
\cline { 2 - 4 } & Males & Females & Males & Females \\
\hline $\begin{array}{c}\text { Numbers of patients } \\
\text { in whom adequate } \\
\text { data was available }\end{array}$ & 33 & 29 & 11 & 6 \\
$\begin{array}{c}\text { Numbers of such } \\
\text { patients in whom } \\
\text { constipation was } \\
\text { a conspicuous } \\
\text { symptom }\end{array}$ & 12 & 5 & 5 & 1 \\
\hline
\end{tabular}

One patient (RI 15183/41) with a Rathké pouch cyst, who is too young to be included in this series, was in hospital no less than five times for either manual removal of faeces or else investigation of chronic constipation. A barium enema showed no abnormality of the large bowel. The constipation was eventually relieved as the child grew older. 


\section{The Biochemical Investigation of the Patient with} Pituitary Disease

In a surgical unit where urgency compels a rapid succession of patients, the biochemical investigation must usually be limited to the minimum compatible with designing the safest treatment and with giving the greatest benefit to the patient. The study of the effects of anterior pituitary failure can be exhaustively and lengthily protracted.

This study involves 17 patients (14 of them males) with pituitary tumour and anterior pituitary failure of greater or lesser degree. Of these patients, nine had completed their treatment (at intervals varying from 11 months to 15 years earlier) and they were readmitted to hospital because of symptoms observed at the follow-up clinic which suggested hypopituitarism. In one such patient symptoms of hypopituitarism had prevented his return to work for over three years, but he took up employment again at the age of 59 within three months of beginning hormone replacement treatment. In another patient still being followed up who was suffering from gross loss of energy and severe dyspnoea, hormone replacement greatly increased his physical capacities and relieved him of his symptoms. In the remaining five similar patients, their increase in well-being and in energy following treatment was uniformly recounted in glowing terms. The desirability of hormone replacement can scarcely be disputed; the questions to be decided are which hormone and in what dose?

From experience with these patients, it can be said that the most important investigation is the water-loading test, repeated with $50 \mathrm{mg}$. cortisone given by mouth four hours before ingestion of the test dose of water. Estimations of the serum sodium and potassium, together with the plasma chlorides, should be performed before carrying out this test. Wynn and Garrod (1955) have warned against the dangers of indiscriminate water loading where water intoxication already exists. They advise that the test should not be carried out when the serum sodium level is below $130 \mathrm{~m}$.Eq./litre. Moreover, it has been the custom here to modify the test load of water according to the capacity of the patient. As mentioned above, some patients with severe hypoadrenalism are accustomed to drink only 750$900 \mathrm{ml}$. of fluid in the whole day. To expect them to consume the full $20 \mathrm{ml}$. per $\mathrm{kg}$. prescribed in the Kepler test (Robinson, Power, and Kepler, 1941) is to vitiate the test in advance by provoking vomiting. No patient has been encountered in whom less than $600 \mathrm{ml}$. could be consumed, and under these circumstances the validity of the test is endorsed if, after the patient ceased to eat or drink at 6.30 p.m. the volume of urine excreted between 10.35 p.m. and 7 a.m. is large (e.g., $300-350 \mathrm{ml}$.) and if the test repeated with preceding cortisone reveals a normal or near-normal metabolism of water. With regard to the maintenance dose of cortisone, only one patient has required thrice daily administration of $12.5 \mathrm{mg}$. of cortisone; the majority do well on $12.5 \mathrm{mg}$. twice daily, while a few are adequately improved on $12.5 \mathrm{mg}$. once a day.

If the patient is co-operative enough, an assessment of the basal metabolic rate (B.M.R.) is desirable, for this will then place treatment with thyroid extract or thyroxine on a firm and rational basis. The lowest B.M.R. encountered in this group of patients has been $-39 \%$. When indicated, the usual dose of dried thyroid extract is $1 \mathrm{~g}$. daily, and a few patients have had this increased to $2 \mathrm{~g}$. daily. Because thyroid hormone may precipitate latent suprarenal insufficiency (e.g., Lerman and Stebbins, 1942) thyroid hormone is never started without first performing a water-loading test, and if cortisone is required thyroid is not begun until a few days with cortisone treatment have elapsed. In the male with adrenal cortical hypofunction, a low output of 17-ketosteroids suggests that gonadal function is also subnormal.

With regard to testosterone, methyl testosterone sublingually has been employed generally, giving $25-50 \mathrm{mg}$. daily to the males, and $5-10 \mathrm{mg}$. daily to the females. Methyl testosterone has been prescribed in most instances for its metabolic (anabolic) effects. Without the patient's express request it appears mischievous to alter a patient's sexual activities through the medium of hormone treatment merely in order to make him approximate to an arbitrary " normal" man.

The blood cholesterol level and the glucose tolerance test do not appear to have any intrinsic value in the planning of therapy. Insulin tolerance tests have not been performed because the waterloading test is a safer and a simpler indicator of the necessity for cortisone. The Thorn test utilizing one intramuscular injection of A.C.T.H. has been shown to be misleading. The intravenous Thorn test (Renold, Jenkins, Forsham, and Thorn, 1952) has not so far been employed. Table III lists the results of some of the biochemical studies performed.

The possible dangers of cortisone therapy, e.g., water retention, masking of infection, elevation of the blood pressure, psychosis, have, with the exception of one case, not been encountered. However, this treatment should not be entered upon unthinkingly or without due care. The following case illustrates the possible dangers of even small doses of cortisone to a patient with long-standing anterior pituitary failure. 
TABLE III

BIOCHEMICAL DATA FROM GROUP OF PATIENTS WITH PITUITARY INSUFFICIENCY ALL REQUIRING SUPPLEMENTARY TREATMENT WITH HORMONES

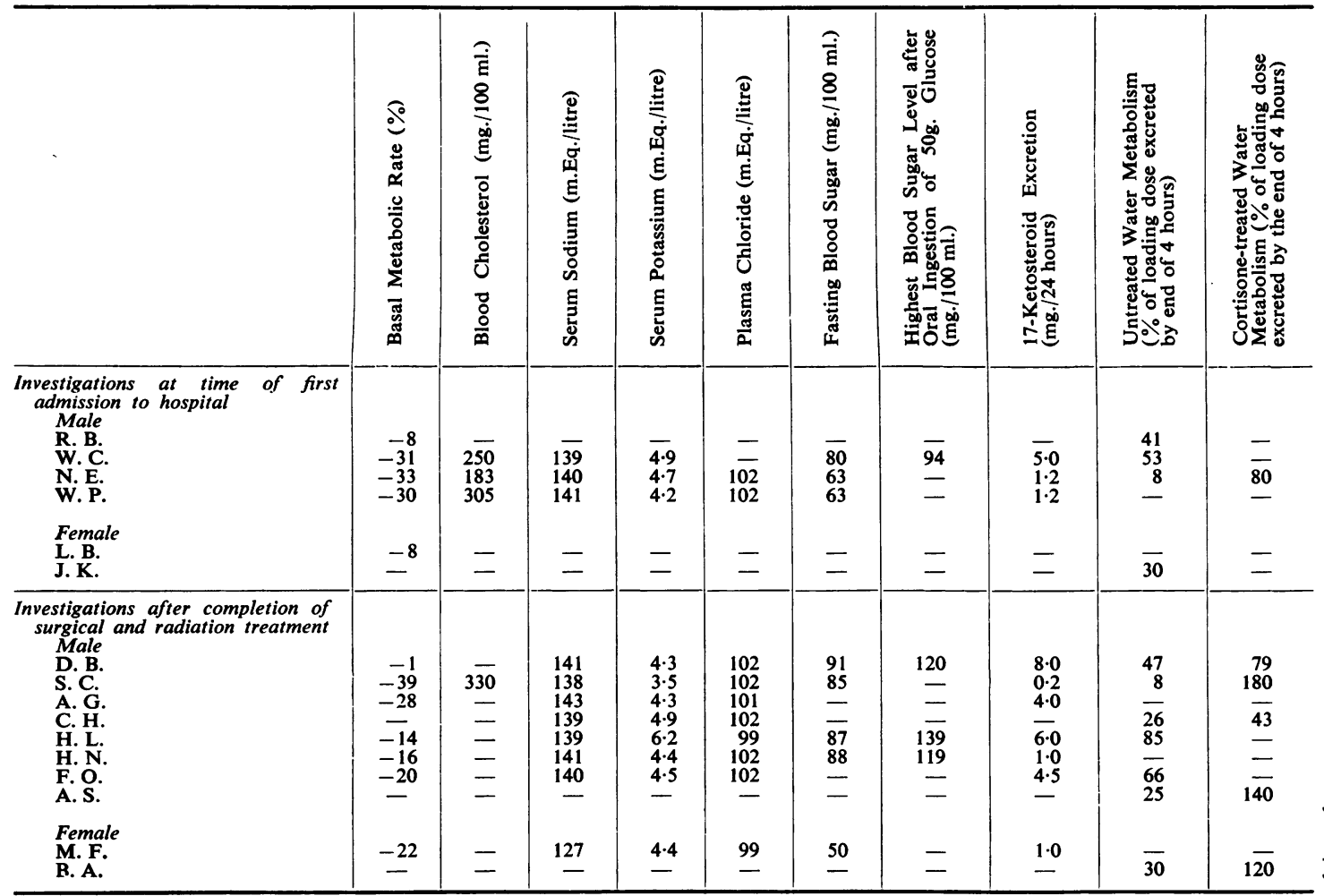

Case 7.-A woman (RI 194934/54) was aged 42 at the time of her first admission in 1939 . Her periods had ceased suddenly 14 years earlier, and from that time on she had suffered from headaches. For 15 months there had been some failure of vision. She had the features of "hypopituitarism", a partial bitemporal hemianopia with preserved visual acuities, and radiographs showed an expanded sella turcica. One course of radiation treatment had been given nine months before admission, and since there was no clear evidence of progressive visual failure, operation was not advised, but further radiation treatment was prescribed. This was effective, so that 15 years later there had been no reduction in the visual acuity in the right eye and only minimal change in the left eye. There was no significant change in the field of vision over the years. In 1954 she was found to be complaining of loss of weight and lack of energy. On going further into her history, it was noted that for several years she had been liable to episodes in which for two days at a time she would lie around the house dozing and scarcely speaking or eating. She would then recover spontaneously. Her ill-health appeared likely to be the result of anterior pituitary failure. The investigations confirmed the desirability of hormone replacement therapy, and she was discharged from hospital taking cortisone, $12.5 \mathrm{mg}$. b.d., dried thyroid, $0.5 \mathrm{~g}$. b.d., and methyl testosterone, $10 \mathrm{mg}$. a day sublingually. Arrangements were made to see her two months later. In the interim, the patient and her family were delighted with her increased mental alertness, her improved vigour and her good appetite. However, she became remarkably thirsty, and five weeks after her discharge developed cedema of the ankles. Two weeks later, although the oedema still persisted, she felt well when she developed an upper respiratory infection with a slight cough. The day before her death she was up and about, running her house, and ate four good meals. The next day she was unwell, ate nothing for breakfast or lunch, but dozed in a chair. After lunch she could not be awakened, but in view of the episodes mentioned above no particular notice was taken of this until late evening, when she was found to be snoring heavily. She died quietly later that night, and at necropsy there was a bilateral bronchopneumonia sufficiently extensive to explain her death, and a pituitary gland in which almost all the glandular tissue had been replaced by extensive fibrosis. Presumably this patient had suffered from secondary adrenal failure for so long that $25 \mathrm{mg}$. of cortisone per day was enough to cause retention of water and to mask the chest infection, with fatal results.

Since this experience, it has been the practice in 
this unit to re-examine patients two to three weeks after cortisone treatment has begun. Two further out-patient visits are generally arranged in the next two months, and from then on the visits may be rapidly spaced out until they conform with those required for supervision of the visual disorder.

\section{Discussion}

The means by which adrenal cortical hypofunction may manifest symptoms or signs referable to the nervous system has not yet been fully elucidated. Mental or intellectual changes may possibly result from decreased cerebral blood supply. This is a notion which appealed to some of the earliest observers of this condition. Greenhow (1875) referred to "The symptoms more directly referable to the nervous system ... which ... may ... be regarded as the effects of some interference with the due blood supply of the great nerve centres ". He went on to say that these symptoms closely resembled the nervous phenomena which sometimes follow copious haemorrhages. It is possible that further experience, together with greater understanding of the hormones of the suprarenal cortex, will show that adrenal cortical insufficiency is not a single entity but has different facets. It is difficult to understand why in one case critical illness develops in association with a grossly disordered biochemical state ( $c f$. Case 1) and in another an equally serious illness occurs when the blood chemistry is far less disordered (cf. Case 2 and Case 1 in Jefferson, 1956). In Case 1 of this paper there was no complicating factor whilst in the other two cases air had been injected inside the skull, and it is possible that hypothalamic disturbances contributed to the onset of the crisis.

Sergent's (1903) description of meningism in adrenal insufficiency so impressed Siredey and Tinel (1907) that they claimed (perhaps somewhat rashly) to have made the diagnosis of Addison's disease when they observed a tuberculous patient with meningeal signs. Of course, this deduction requires qualification, but their enthusiasm for the importance of this sign emphasizes an occurrence which could not readily have been anticipated. It is interesting to speculate how this sign develops. A clue may be provided by Case 1 . In this instance it will be recalled that at lumbar puncture 48 hours before the circulatory collapse only $0.5 \mathrm{ml}$. of clear fluid was withdrawn. Since the fluid was uncontaminated by blood, it suggests that the needle point was correctly placed, but that the pressure was so low or that the fluid was so much less abundant than is usual that almost none could be withdrawn. The morning of the day of the circulatory collapse, no fluid could be aspirated at all but later that day, after liberal intravenous fluid and after the patient's blood pressure had been restored and he had passed urine, a lumbar puncture was successfully performed and $3 \mathrm{ml}$. of fluid was removed. In Case 2 the lumbar puncture pressure was only $40 \mathrm{~mm} . \mathrm{H}_{2} \mathrm{O}$ and in another post-operative case the lumbar puncture pressure was found to be as low as $35 \mathrm{~mm} . \mathrm{H}_{2} \mathrm{O}$. A low cerebrospinal fluid pressure does not necessarily accompany adrenal cortical hypofunction, but the cases quoted above indicate that low pressure and adrenal failure may be at times associated.

That a gross reduction in the amount of intracranial cerebrospinal fluid can give rise to meningism is strongly suggested by the following events.

A man aged 47 (RI 72880/55) was struck by a baseball on the left side of his forehead five days before admission to this hospital. He did not lose consciousness, nor did he at any time have any abnormal neurological signs, but he had to attend a hospital in order to have a left frontal laceration sutured. He at once developed what was later proved to be left-sided cerebrospinal rhinorrhoea and that same evening he had a severe headache and a stiff neck. From the fact that he remained well for the next four days it is unlikely that he had any meningeal infection at that stage and one may with reasonable certainty ascribe his neck stiffness to the results of the escape of the cerebrospinal fluid. With the brain deprived of its surrounding fluid painsensitive structures might easily become distorted thus providing a basis for the reflex development of neck stiffness.

A pituitary tumour not infrequently extends upwards to distort the third ventricle and cause intermittent hydrocephalus. This development would very probably be signalled by correspondingly intermittent attacks of headache and vomiting. However, in the presence of hypopituitarism, headache and vomiting may be no more than manifestations of adrenal cortical hypofunction and they thus may be corrected by replacement therapy. Rarely, in the presence of adrenal cortical hypofunction headache may result from the effects of cerebral oedema associated with adrenal failure. This subject has recently been discussed and illustrated elsewhere (Jefferson, 1956).

If it be agreed that for the patient with a " pituitary tumour" hypopituitarism may be closely equated with adrenal cortical hypofunction, the figures quoted above indicate that the male suffers from this disability more frequently than the female. In this connexion the following observations are of interest. Greenhow (1875) collected all the described cases of Addison's disease from the literature and concluded that this condition was " much more frequent in the male sex ". Many years later Guttman (1930), from a study of the published literature, showed that when 
tuberculosis of the suprarenals was the cause of the disease there were nearly three times as many males with Addison's disease as there were females. These findings would suggest that the metabolism of the male is more readily disorganized by adrenal cortical hypofunction than is that of the female, for it is unlikely that the tuberculous process was more destructive of the suprarenal cortical tissue in the male sex than in the female sex.

Occasionally, spontaneous water intoxication occurs in anterior pituitary hypofunction (e.g., Wynn and Garrod, 1955). Epilepsy is an uncommon accompaniment of a pituitary chromophobe adenoma but when it forms a troublesome feature of the post-operative period it is worth considering whether water intoxication could be contributing to the difficulties of control of the epilepsy. It is possible to say this because induced water retention is one of the means whereby a potentially epileptic lesion may be provoked into a discharge (McQuarrie and Peeler, 1931). Thus, if in an epileptic patient who may have secondary suprarenal failure, the metabolism of water proves to be abnormal but can be corrected by cortisone, then cortisone therapy must be included among the measures designed to control the epilepsy.

Study of the clinical data of this series of cases emphasizes that a dry skin may be a feature of " hypopituitarism ". Furthermore, Cases 1, 2, and 3 and the suggestive evidence of Case 4 and of a female patient (RI 37587/45) in the series indicate that when a diagnosis of adrenal cortical failure can be entertained the finding of a dry scaling of the skin, particularly of the skin of the face, increases the likelihood of this diagnosis being correct. In confirmation of this observation it is interesting that in a paper by Aitken and Russell in 1934 one of the outstanding clinical features of a patient with a pituitary chromophobe adenoma was dry scaling of the facial skin.

With regard to the incidence of rheumatism, it is not suggested that the presence of a pituitary tumour causes rheumatism, but it seems possible that anterior pituitary failure leading indirectly to lessened production of cortisone and related substances may unmask a pre-existing tendency to rheumatism. Sugar (1953) also found an association between rheumatism and anterior pituitary failure.

It is now generally recognized by neurological surgeons that the use of A.C.T.H. or of cortisone lessens the mortality in operations in the region of the pituitary gland and leads to a smoother postoperative phase. Convincing evidence on this point is provided, for example, by the papers of Ingraham, Matson, and McLaurin (1952) and of Tytus, Seltzer, and Kahn (1955). The problem now confronting the neurosurgeon is whether all patients with these lesions should be given cortisone, and, if selective administration is preferred, it becomes necessary to be able to recognize patients who require such treatment, either to cover the operation alone, or subsequently and for a longer time. It is necessary to stress the value of the water-loading test (repeated with a preceding dose of cortisone) in this class of patient. Moreover, experience in this Department suggests that in order to recognize the largest possible number of patients with secondary adrenal failure an electroencephalogram should be performed from time to time on patients who have had treatment for pituitary " tumours". This subject has been discussed more fully elsewhere (Boselli and Jefferson, 1957).

The dangers of allowing adrenal cortical hypofunction to persist untreated are very real, and to anyone who has studied a series of affected patients the morbidity and the mortality from this cause speak for themselves.

\section{Summary}

It is stressed that adrenal cortical failure may have neurological symptoms and signs among its present- -0 or ing features. Meningism may also occur in this disease. To illustrate these points two unusual cases $\overline{\mathbb{D}}$ of Addison's disease are described.

Adrenal cortical hypofunction may influence the presenting features of patients with " pituitary tumours". This influence may be manifest before visual signs have occurred, or in the early postoperative period, or it may make a gradual appearance (perhaps after radiation treatment) in the years that follow. Illustrations of these occurrences are provided, and the dangerous consequences of failure to recognize these signs of adrenal failure are emphasized.

Of 135 cases of pituitary chromophobe adenoma, " hypopituitary" features (among which features, adrenal cortical hypofunction figures largely) were present in $66 \%$ of the males and in $37 \%$ of the females. The sex distribution between a much smaller group of Rathké pouch cysts (31 cases) was all but equal.

The dangers of the untreated hypopituitary state are underlined by the fact that of 61 known eventual deaths in this series no fewer than 26 were considered to be linked with secondary suprarenal failure.

The possible association with adrenal cortical hypofunction of a dry scaling skin (particularly a scaliness of the facial skin), of rheumatism, and of severe constipation is emphasized.

The results of the biochemical investigation of some of these patients is briefly recounted, and the conclusion is drawn that when adrenal cortical 
hypofunction may be present study of the patient's capacity to excrete rapidly a "loading" dose of water provides both the simplest and one of the most sensitive indications of this dysfunction. The test gains in value when repeated with a preceding dose of cortisone, and the two sets of results are compared.

The improvement produced by hormone replacement therapy in a group of 17 patients all of whom received cortisone is briefly described.

I am grateful to Mr. Joe Pennybacker for advice during the preparation of this paper. The paper was prepared during the author's tenure of a Nuffield Foundation Fellowship.

\section{REFERENCES}

Aitken, R. S., and Russell, D. S. (1934). Lancet, 2, 802.

Boselli, F. and Jefferson, A. A. (1957). Electroenceph. clin. Neuro physiol., 9, 275.

Cushing, H. (1913). Amer. J. Insan., 69, 965.

Engel, G. L., and Margolin, S. G. (1941). Arch. Neurol. Psychiat. (Chicago) $, 45,881$.
Foley, M. P., Snell, A. M., and Craig, W. McK. (1939). Amer. J. med. Sci., 198, 1 .

Frette, L. (1913). Contribution à l'étude de l'Insufficance Surrénale aiguè à forme encéphalopathique. Thèse. Paris.

Goetsch, E. (1914), Ouart. J Med., 7, 173.

Gosset, A. E. M. (1941). L'Encéphalopathie Addisonienne. Thèse. Paris.

Greenhow, E. H. (1875). On Addison's Disease, being the Croonian Lectures for 1875. Longmans, Green and Co., London.

Guttman, P. H. (1930). Arch. Path. (Chicago), 10, 742, 895.

Ingraham, F. D., Matson, D. D., and McLaurin, R. L. (1952). New. Engl. J. Med. 246, 568.

Jefferson, A. (1956). Journal of Neurology, Neurosurgery and Psychiatry, 19, 21.

Klippel, M. (1899). Rev. neurol. (Paris), 7, 898.

Lebrun, R. (1937). Contribution à l'étude de l'encéphalopathie addisonienne. Thèse. Paris.

Lerman, J., and Stebbins, H. D. (1942). J. Amer. med., Ass. 119, 391.

McQuarrie, I., and Peeler, D. B. (1931). J. clin. Invest., 10, 915

Renold, A. E., Jenkins, D., Forsham, P. H., and Thorn, G. W. (1952). J. clin. Endocr., 12, 763.

Robinson, F. J., Power, M. H., and Kepler, E. J. (1941). Proc. Mayo Clin., 16, 577.

Rushton, J. G., Cragg, R. W., and Stalker, L. K. (1940). Arch. intern. Med., 66, 531 .

Sergent, E. (1903). Presse méd., 11, 813.

Siredey, A., and Tinel, C. (1907). Bull. Soc. méd. Hôp., Paris. 3 ser. 24, 145 .

Sugar, M. (1953). J. clin. Endocr., 13, 1118.

Tytus, J. S., Seltzer, H. S., and Kahn, E. A. (1955). J. Neurosurg. $12,555$.

Wynn, V., and Garrod, O. (1955). Brit. med. J., 1, 505. 